\title{
SABERES SOCIOCULTURAIS E LETRAMENTOS MÚLTIPLOS DE ESTUDANTES DA ESCOLA NO/DO CAMPO ${ }^{1}$
}

\author{
SOCIOCULTURAL KNOWLEDGE AND MULTIPLE LITERACY OF SCHOOL STUDENTS \\ IN / FROM THE RURAL AREA
}

Marta Divina Pereira da Silva ${ }^{2}$
Rosineide Magalhães de Sousa ${ }^{3}$

Resumo: O artigo analisa textos de estudantes do sétimo ano, do Ensino Fundamental de uma escola pública do campo, de Barreiras - BA. Nessa análise, consideramos o contexto social, econômico e cultural a que pertencem esses estudantes. Metodologicamente, trabalhamos etnografia de sala de aula, realizando: observação, descrição e análise, e participação colaborativa, com a aplicação de sequência didática, e o uso do texto biográfico, subsidiando a produção do texto autobiográfico. À luz da teoria dos letramentos múltiplos e da leitura sociolinguística, foi possível reconhecer a necessidade da observação do lugar de pertença do estudante no/do campo e suas distintas práticas de conhecimento de leitura e de escrita, bem como a importância da valorização dessa cultura no contexto escolar. Encontramos nos textos escritos, evidentes demarcações dos fatores socioculturais de seu autor, com múltiplas expressões e marcas linguísticas que identificam o lugar de pertencimento que, em certos casos, não são compreendidas em sala de aula.

Palavras-chave: Práticas de letramentos; fatores socioculturais; escola no/do campo.

Abstract: This work analyzes texts of seventh year students from elementary school in a public school in the rural area, in the municipality of Barreiras - BA. In this analysis, we consider the social, economic and cultural context to which these students belong. The research methodology used for data generation was classroom ethnography, with the following procedures: observation, description and analysis, and collaborative participation, with the application of didactic sequence, using the biographical text, subsidizing the production of the autobiographical text. Through this research, in the light of the theory of multiple literacies and sociolinguistic reading, it was possible to recognize the need to observe the place of belonging of the student in / of the rural area and its different practices of knowledge of reading and writing, as well as the importance valuing this culture in the school context. We find in the written texts, evident demarcations of the socio-cultural factors of their author, with multiple expressions and linguistic marks that identify the place of belonging that, in certain cases, are not understood by teachers in the classroom.

Keywords: Literacy practices; sociocultural factors; school in/from the rural area.

\section{Introdução}

Neste artigo, analisamos produções escritas de estudantes de uma escola no/do campo, do Município de Barreiras- BA, com o objetivo de descrever os saberes socioculturais e

\footnotetext{
${ }^{1}$ Este trabalho traz dados da dissertação de mestrado intitulada "A Diversidade Linguística e os Letramentos Múltiplos de Produções Escritas na Escola no/do Campo" vinculada ao grupo de pesquisa SOLEDUC (Sociolinguística, Letramento Múltiplos e Educação), coordenado pela Professora Doutora Rosineide Magalhães de Sousa da Universidade de Brasília.

${ }^{2}$ Universidade de Brasília, Brasília, DF, Brasil.

${ }^{3}$ Universidade de Brasília, Brasília, DF, Brasil.
} 
letramentos múltiplos nesses textos, uma vez que as práticas sociais, que permeiam suas vivências, são associadas à diversidade linguística e influenciam no contexto da sala de aula. É importante destacar, que esta investigação é pontuada na experiência realizada há dez anos pelo projeto de Múltiplos Letramentos desenvolvido na Licenciatura em Educação do Campo (LEDOC), da Faculdade UNB Planaltina, pelo grupo de Pesquisa Sociolinguística, Letramentos Múltiplos e Educação (SOLEDUC).

Na perspectiva da etnografia de sala de aula, propomos, neste estudo a produção de uma autobiografia, pois acreditamos que é importante o conhecimento da história das pessoas investigadas pelas perspectivas delas em seus textos, orais ou escritos. Nesse caso, os estudantes regularmente matriculados em turmas de sétimo ano, do Ensino Fundamental de uma escola pública no/do campo de Barreiras (BA)

Nesse contexto, foi utilizada, como elemento inicial para geração de dados, a produção de um texto autobiográfico produzido pelos estudantes e pela professora, com o intuito, primeiro, de registar a realidade social, econômica e cultural a que eles pertencem. Esse gênero foi escolhido porque oferta um reconhecimento da vivência com o mundo da leitura e da escrita desses participantes, subsidiando todo o restante do processo de geração de dados. Vale ressaltar, que o texto autobiográfico parte da instrumentalização da etnografia para a pesquisa sociolinguística de sala de aula.

Com isso, foram realizadas observações em sala e posterior desenvolvimento de uma sequência didática. Em um primeiro momento, apresentamos exemplos de biografias de artistas consagrados na cultura popular brasileira, a exemplo de Luiz Gonzaga e Patativa do Assaré, associando as obras de ambos e demonstrando aos estudantes a forte relação desses artistas com a cultura do campo e do Nordeste. Para o desenvolvimento da sequência didática, oportunizamos a audição da música "A triste partida" e destacamos que a letra é pertencente a Patativa do Assaré, tendo se tornado um grande sucesso na voz de Luiz Gonzaga. Em seguida, solicitamos aos estudantes que produzissem suas próprias biografias. Propusemos ao longo da oficina reelaborações do texto no intuito de que pudessem compreender a estrutura do gênero ora trabalhado.

Os textos produzidos durante essa oficina foram essenciais para observamos características socioculturais que se encontram na estrutura linguística dos textos destes estudantes para que fosse possível compreendermos como eles concebem o texto escrito em suas vivências, em sua leitura de mundo, configurando assim letramentos múltiplos.

\section{A Educação no/do Campo e os Letramentos Múltiplos}

O direito à educação foi negado aos povos do campo pelo Estado brasileiro por muito tempo. Face essa histórica exclusão, o campo detém altos índices de analfabetismo e baixa escolarização. Dito isso, é imperioso mencionar que tal cenário perdurou por um longo período porque o governo e a oligarquia agrária não tinham interesse em escolarizar os sujeitos do campo, já que esta parcela da população é formada majoritariamente por escravos, mestiços ou imigrantes que vieram trabalhar e desenvolver a agricultura e, assim sendo, não detinha poder aquisitivo, não podendo gerar retorno financeiro.

Essa realidade não mudou até a década de 1940, quando, então, os governantes são pressionados pelos bancos internacionais a diminuírem as taxas de analfabetismo na zona urbana e rural, do Brasil, para obter empréstimos junto a países desenvolvidos. Em decorrência disso, no ano de 1946, a escolarização rural foi forte pauta de discussão governamental. Mesmo assim, somente nas décadas posteriores é que os Ministérios da Agricultura, da Educação e da Saúde criaram projetos para o desenvolvimento humano no meio rural. 
Os primeiros passos em direção à educação no/do campo foram muito controversos, pois a intenção era fazer dos sujeitos do campo típicos "fazendeiros americanos". O ideário apresentado não foi alcançado, pois partia-se de uma realidade totalmente desvinculada ao campo brasileiro e que tinha como foco somente a preparação de mão-de-obra qualificada para a agricultura mecanizada. Logo, esses programas não obtiveram êxito porque a atividade agrícola no Brasil era rudimentar, portanto, desprovida de máquinas, como ocorria nos países americanos.

Com o ideário de formar mão-de-obra qualificada para atuar no campo e assim aumentar o desenvolvimento do país, foi formulado e implementado, em 1945, o projeto de "aldeia rural", e visava atender às especificidades culturais, administrativas e industriais da área ocupada pelo conjunto de aldeias. Atrelados a ele, surgem, anos depois, os movimentos de educação popular e a campanha de educação de adultos.

Ainda perseguindo o desejo de tornar o Brasil um país desenvolvido, surge no início da década de 60 o "Plano Nacional de Alfabetização", coordenado por Paulo Freire, tendo como apoio filosófico-ideológico os valores e o universo sociolinguístico-cultural das classes populares. Essa proposta visou romper a dicotomia entre o contexto social, político, econômico e cultural dos estudantes e propunha a aproximação desses elementos supracitados usando os "temas geradores", extraídos da realidade na qual os sujeitos estavam inseridos (FREIRE, 1970). Nesse sentido, suscitava a problematização da condição de opressão vivenciada pelas pessoas e criticava a educação bancária - aquela que preconizava que os docentes eram os detentores dos conhecimentos e os estudantes eram tábulas rasas, cabendo ao primeiro encher os segundos com os saberes e estes, de forma passiva, somente receber os conteúdos sem refletir sobre eles.

Estabelecendo parceria com o Ministério da Educação, o governo criou, posteriormente, o Programa Nacional de Ações Sócio-Educativas e Culturais para solucionar o problema do analfabetismo no meio rural, sendo eles o PRONASCECe o EDURURAL, que, segundo Leite:

Esse projeto tentou viabilizar novos conceitos sobre educação no meio rural, produzindo veemente crítica aos currículos urbanos introduzido na zona rural e, a partir daí, criar "autonomia" pedagógica de modo a valorizar o trabalho de professores e alunos, enfatizando a realidade campesina (LEITE, 1999, p. 51).

Esses programas propunham a vinculação entre educação e o contexto sócio-histórico, posto que ainda não se tinha uma educação do campo, mas sim educação no campo. Nesse contexto, consideravam-se as matrizes socioculturais dos estudantes. Por muito tempo esse cenário continuou sem mudanças significativas até que nos anos 80 ocorreu os primeiros movimentos populares que reivindicam que a educação passasse a ser para todos, independente do espaço geográfico onde se vivia.

Nesse interim, fora promulgada a Constituição de 1988, que determina em seu artigo 205, "a educação direito de todos e dever do Estado e da família". Isso garantia, perante a letra da lei, que os povos do campo tivessem escolarização. Já em 1989 foi criada a Comissão Nacional de Alfabetização, que começou a idealizar a Lei de Diretrizes e Bases da Educação Nacional (LDB, 9394/96), documento significativo para a afirmação da Educação no/do Campo, pois propõe, em seu artigo 28, a adequação da escola aos sujeitos e à vida do campo.

As adaptações estabelecidas nos artigos da LDB lançam as primeiras sementes para a criação da categoria da Educação do Campo como uma educação específica, que deve estar vinculada às matrizes socioculturais dos estudantes do meio rural. Mesmo assim, ainda se faz necessário tecer a crítica, pois os sujeitos do campo ainda tinham um longo caminho a percorrer para construção de um projeto educativo pensado com e para eles, e ainda precisava lutar por outros direitos negados, 
como acesso a serviços públicos básicos, como saúde, saneamento, estradas entre outros de igual relevância para que haver qualidade de vida no local onde residem.

Diante disso, segundo Vendramini (2007, p. 127), "os movimentos sociais levantam a bandeira da reforma agrária, propõem a redistribuição de terras e de riquezas, ocupam áreas consideradas improdutivas, exigem trabalho e escola para seus filhos". Para reafirmar o direito à educação, foram realizadas diversas conferências sobre o tema no país.

A educação rural passa então a ser Educação do Campo e esse segmento educacional passa a se constituir o centro de debates e formulação de políticas públicas. Para Arroyo (2004), é preciso superar a visão pejorativa de "escolinhas cai não cai”, para que passem a ser vistas como espaços que formam os estudantes, dando a esses saberes científicos e formação humana para lutarem para transformação da sociedade, de modo a diminuir as disparidades sociais.

No bojo dos avanços conquistados pelos estudantes do campo, surgem as Diretrizes Operacionais para a Educação Básica nas Escolas do Campo. Esse documento aborda aspectos acerca da identidade dos povos do campo, da organização escolar, do currículo, da formação de professores, entre outros aspectos relevantes. As Diretrizes Operacionais para a Educação Básica nas Escolas do Campo (2001, p. 22) determinam no artigo $2^{\circ}$ parágrafo único:

A identidade da escola do campo é definida pela sua vinculação às questões inerentes à sua realidade, ancorando-se na temporalidade e saberes próprios dos estudantes, na memória coletiva que sinaliza futuros, na rede de ciência e tecnologia disponível na sociedade e nos movimentos sociais em defesa de projetos que associem as soluções exigidas por essas questões à qualidade social da vida coletiva no país (DIRETRIZES OPERACIONAIS PARA A EDUCAÇÃO BÁSICA NAS ESCOLAS DO CAMPO, 2001, p. 22).

Expõe-se, pois, a necessidade de vínculo entre o projeto educativo da escola com as matrizes histórico-culturais dos educandos do campo, formada por uma diversidade de sujeitos que tem, também, múltiplos letramentos (SOUSA et al., 2016). Dito de outro modo, a escola no/do campo deve incorporar os conteúdos específicos ligados à vida desses sujeitos, fazendo com que eles se sintam pertencentes ao ambiente educativo, porque conseguem ver vínculos entre seu contexto e os saberes tratados na escola.

Nessa lógica é necessário mencionar que a Educação do Campo é formada, segundo Molina (2012), pela tríade Campo, Políticas Públicas e Educação - três elementos que são essenciais para a existência da Educação do Campo. O campo é o espaço de vida, de produção agrícola de cultura, e sem sua materialidade não há como existir sujeitos morando nesse perímetro. As políticas públicas são primordiais para a permanência do homem no meio rural, pois, ele precisa ter acesso à saúde, ao saneamento, a estradas e a créditos agrícolas que garantam sua produção e educação.

É preciso lutar pela posse desse espaço de vida, trabalho, pela sua cultura e para que a Educação do Campo continue vinculada às matrizes formativas que lhe deram origem, ou seja, à luta por outro projeto de campo e pela formação de indivíduos humanos e críticos.

Desse modo, a escola poderá "contribuir para a formação de novas gerações de intelectuais orgânicos capazes de conduzir o protagonismo dos trabalhadores do campo em direção à consolidação de um processo social contra-hegemônica" (MOLINA; SÁ, 2012, p. 327). Ela, então, permitirá a emancipação dos sujeitos e formando-os para a luta social, possibilitando a eles realizar transformações sociais.

Quanto aos Letramentos múltiplos, para que possamos, primeiramente, entender o termo letramento em um sentido mais amplo, buscamos compreender as discussões acerca de grandes estudiosos como, Rojo (2009), por exemplo, para conceituar as práticas sociais de escrita e leitura, 
O "significado do letramento" varia através dos tempos e das culturas e dentro de uma mesma cultura. Por isso, práticas tão diferentes, em contextos tão diferenciados, são vistas como letramento, embora diferentemente valorizadas e designando a seus participantes poderes também diversos (ROJO, 2009, p. 99).

A partir das premissas de Rojo, podemos entender o letramento como os diversos meios que as pessoas possuem de interpretar o mundo que as cerca, ainda que não sejam alfabetizadas. Isso acontece devido à multiplicidade de letramentos existentes no mundo. Podemos definir como Letramento, por exemplo, as práticas sociais de um trabalhador rural: ele tem um conhecimento específico acerca da relação do solo com o meio ambiente e as etapas e épocas de plantação e colheita. Além disso, mesmo não sabendo ler ou escrever, tem conhecimentos baseados no senso comum, que geralmente são passados de pai para filho ou aprendidos por meio de conversas com amigos, entre outras formas.

Com foco específico nas aulas de Língua Portuguesa, é preciso defendermos a uma implantação de um programa de ensino que vise à educação linguística. Para Antunes (2003), esse programa parte da quebra de conceitos já construídos e de paradigmas que existem dentro das sociedades, bem como alguns mitos. Nesse seguimento, é importante que haja uma abordagem que privilegie a cultura do estudante e valorize suas habilidades em vista das manifestações da linguagem em benefício da sua atuação social. Para isso, é necessário que a instituição escolar amplie "os fundamentos teóricos acerca do que é uma língua, do que é ensinar, do que é aprender" (ANTUNES, 2003, p. 40). Assim, dentre várias práticas, o professor poderá promover a formação do cidadão.

\section{Análise de dados: revelando a cultura do/no campo por meio de letramentos múltiplos}

As discussões em torno do conceito do termo letramento perpassam o mero sentido de alfabetismo, o que nos direciona ao fato de que o cidadão ser letrado não significa simplesmente ser alfabetizado. Existem práticas diversas dentro da sociedade que estão fora dos muros da escola e circulam em diversos contextos socioculturais. Tratamos à luz do conceito de Rojo (2009) acerca dos letramentos múltiplos para uma análise de como eles se apresentam na escrita dos estudantes participantes desta investigação.

Destacamos, para isso, que optamos por selecionar fragmentos dos textos originais com a finalidade de dialogar sobre os traços culturais que estão impressos na escrita do gênero textual na prática do letramento escolar. As figuras apresentadas serão os fragmentos das autobiografias produzidas pelos estudantes.

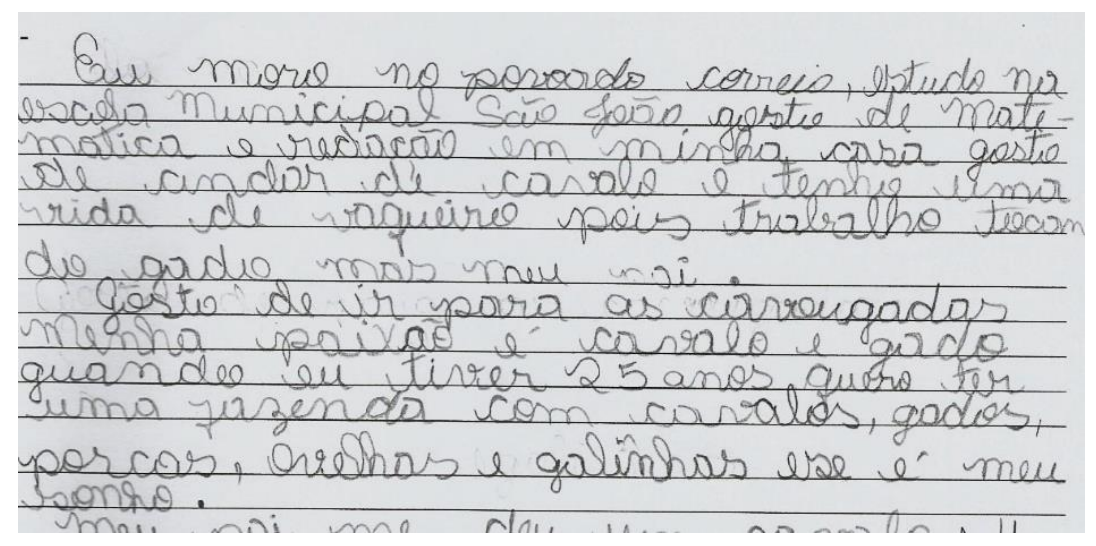

Figura 1 - Fragmento de texto - Fonte: arquivo pessoal de M. D. 
O fragmento de texto apresentado acima nos remete a questões vivenciadas pelo estudante junto à sua família. São perceptíveis os traços de práticas de letramento escolar a partir da utilização de algumas palavras e/ou expressões que reportam à vivência de quem escreve.

Primeiramente, tomemos como norte para essa primeira análise o fato da referência às disciplinas de preferência escolar serem matemática e redação. Apesar dessa afirmação, o estudante em questão desconhece alguns elementos linguísticos essenciais à construção do texto, como a paragrafação e os elementos gramaticais.

Entretanto, apesar dessa observação inicial, o fragmento destaca um conhecimento e/ou prática realizados fora da escola que podem ser reconhecidos como habilidade para o desenvolvimento de uma prática de letramento em um contexto sociocultural que difere do conhecido dentro da escola. Nele, podemos verificar que o estudante descreve a vivência de sua comunidade e de sua família. A princípio, a preferência pela cavalgada e o contato com os animais nos remontam a contextos distintos do ambiente escolar, mas que trazem consigo conhecimentos que evidenciam outras práticas de letramento.

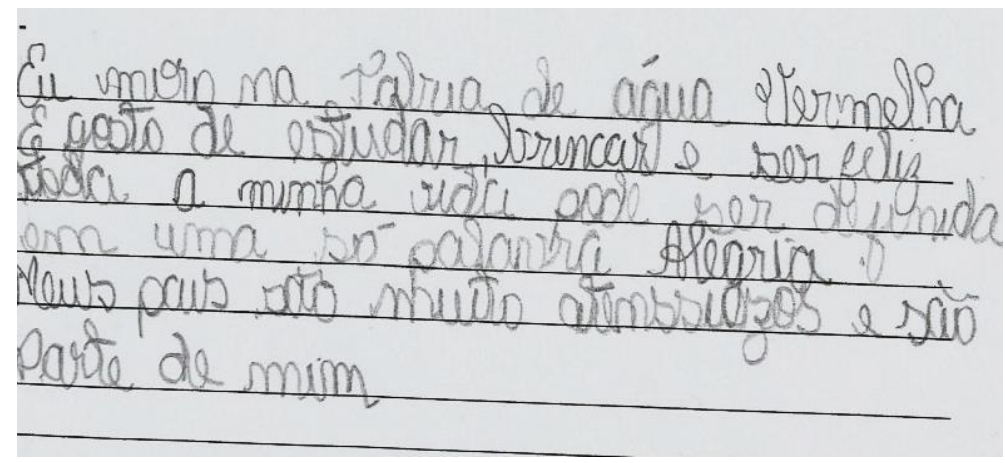

Figura 2 - Fragmento autobiográfico - Fonte: arquivo pessoal de M. D.

Rocha (2013), em sua tese de doutoramento, defende a ideia de que "a criança, independentemente de sua origem, se de família altamente letrada ou não, vai precisar do auxílio do professor para conseguir compreender a arte da escrita". Dessa forma, ao propormos a produção textual em questão, procuramos aclarar as etapas pré-estabelecidas para facilitar a orientação da escrita, mas, mesmo assim, alguns estudantes ratificaram os problemas em produzir. Vale lembrarmos aqui que o processo de acompanhamento deve ser realizado durante todo o percurso escolar.

O próximo texto, apesar de sua pequena extensão, é a produção completa do estudante e não um fragmento dela, apesar de mantermos essa denominação em sua análise. É importante que possamos observar os pequenos textos com respeito e com um olhar de agente letrador (BORTONI-RICARDO, MACHADO e CASTANHEIRA, 2010), pois cada estudante, como discutido, possui uma origem distinta e com isso, práticas de letramentos também diferentes. No processo de incentivo e realização da escrita, cabe ao professor mediar e incentivar a construção ou desenvolvimento dessa prática de letramento para uma melhor aquisição de habilidades leitoras e escritoras. 


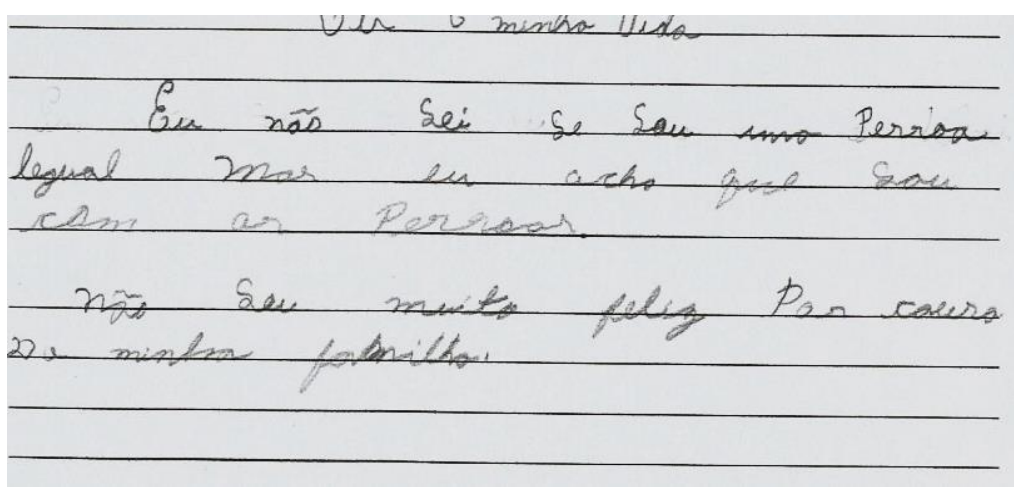

Figura 3 - Fragmento autobiográfico - Fonte: arquivo pessoal de M. D.

O vazio que se apresenta na leitura inicial é preenchido a partir do momento que retornamos ao texto com um olhar mais atento, sensível e intimista. Observamos que esse estudante traz em sua pequena autobiografia mais informações do que as palavras escritas conseguem descrever. Com a indefinição de ser ou não uma pessoa "legal", percebemos que ele apresenta insegurança quanto à sua própria condição identitária. Esses subentendidos nos remetem a eventos sociais vazios de sentimentos, poucas relações de amizade e quase nenhuma participação em redes sociais que o possibilitem distintas práticas de letramento.

É mais latente observarmos a maneira como descreve, ou em outras palavras, a forma como designa culpados para uma possível "infelicidade". Em muitos casos, o professor necessita ter um olhar investigativo acerca da escrita do estudante, pois é com e por meio dela que os estudantes podem encontrar maneiras de "pedir socorro". Dessa forma, o professor, a partir de maior envolvimento dentro sala de aula, pode levar esse estudante a superar sua condição de limitações, não semente relacionadas à carência emocional e afetiva, como também à sua condição social. Talvez esse estudante consiga transcender e encontrar caminhos que o despertem à leitura e, consequentemente, ao prazer pela leitura.

Já no fragmento seguinte, teremos informações mais explicitas sobre os eventos e a práticas de letramento que ocorrem em outros ambientes distintos do espaço escolar. Observemos as situações ou as práticas descritas neste trecho destacando cinco palavras, que podemos considerar as palavras-chave para identificar os itens desta investigação: futebol, casa, obrigações, brincar e faleceu.

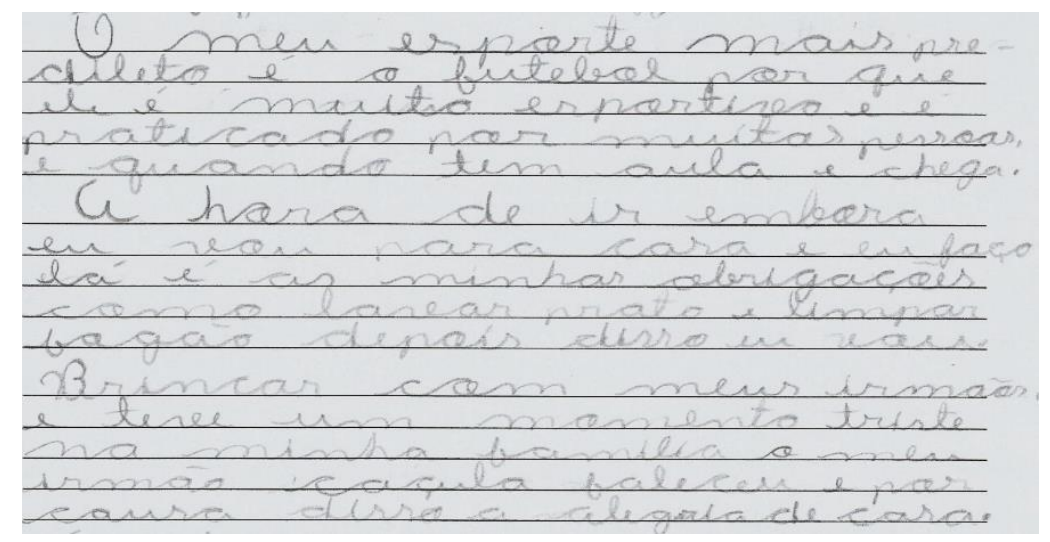

Figura 04 - Fragmento autobiográfico - Fonte: arquivo pessoal de M. D.

Ao apresentarmos as pistas para observar o fragmento, notamos que essas abrem portas para vislumbrarmos os momentos vivenciados pelo estudante que redigiu essa biografia. Em 
primeiro lugar, o esporte em destaque, o futebol, é carregado de práticas que evidenciam os letramentos múltiplos. Vejamos como exemplo as técnicas que são utilizadas em campo, a função dada a cada jogador e como ele vai agir antes, durante e após o jogo. Seja numa "pelada" com os amigos, ou em um campeonato profissional, existem regras que devem ser conhecidas, e seguidas. Existem casos em que são formadas escolinhas de futebol para que meninos e meninas possam aprender essas técnicas, mas em outros muitos casos, essas crianças e esses jovens aprendem em pequenos grupos de sua comunidade.

Outras pistas para essa investigação são as palavras "casa" e "obrigações": atentemo-nos para o fato de que há um complemento de sentido para ambas, pois essas obrigações a que ele se refere são as tarefas de casa, atividade rotineiras que, muitas vezes, necessitam de um aprendizado prévio. Esse estudante, por exemplo, pode receber tarefas desde arrumar o quarto a escrever lista de compras, ou, em alguns casos, em que os pais são donos de pequenos mercados no povoado, ajudam com a organização dos itens das prateleiras ou compras de produtos. Sendo assim, as práticas de letramento dentro do contexto em que ele vive articulamse aos conhecimentos das ciências que são ensinadas pelo letramento escolar.

Também vemos duas palavras que nos remetem a situações distintas, mas que podem ser vislumbradas no contexto da comunidade em que ele vive. As brincadeiras das quais ele participa são brincadeiras na rua da comunidade rural, em pequenos grupos de amigos, pois a localização da comunidade oportuniza que isso ainda possa ocorrer. Com isso, existem eventos de letramento que evidenciam ações rotineiras, a exemplo das brincadeiras de pega-pega, futebol, esconde-esconde, adedonha, dentre outras brincadeiras da comunidade (STREET, 2014).

Por fim, temos a palavra "faleceu" nesse trecho. Uma vez que o irmão do estudante tenha falecido, houve toda uma preparação até o momento do sepultamento. Na vivência do velório, esse estudante participou de pequenos grupos de orações, que são parte da cultura local. Essas orações são lamentações que, segundo algumas religiões, preparam a passagem das almas para o "reino dos mortos". Logo, esse triste evento também compõe uma prática letramento que ocorre no contexto religioso.

O trecho seguinte trará a nítida percepção de que o estudante em questão também apresenta dificuldades no que se refere ao contexto do letramento escolar. Para exemplificar essa asserção, devemos nos deter tanto aos aspectos estruturais no texto, quanto aos desvios relacionados ao uso de elementos linguísticos inerentes à produção escrita.

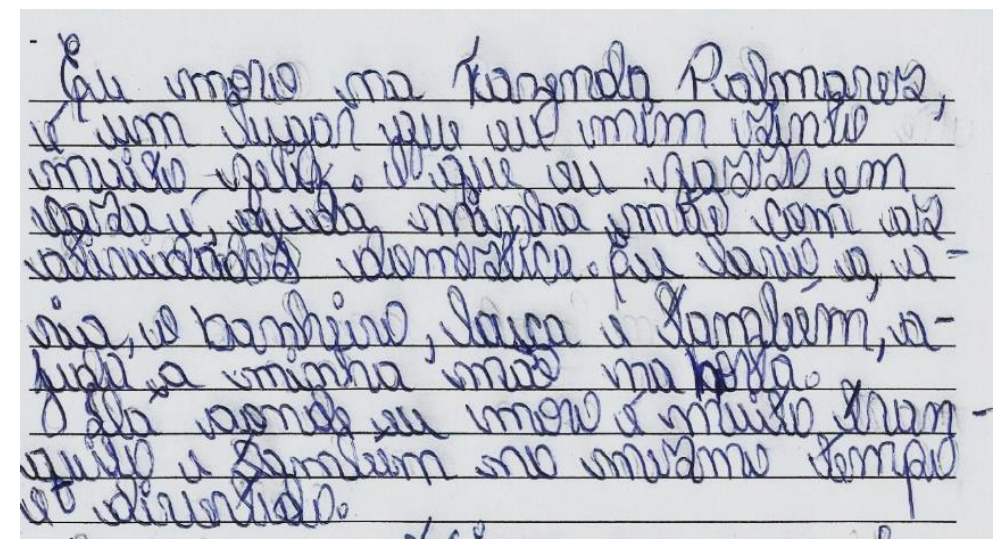

Figura 5 - Fragmento autobiográfico - Fonte: arquivo pessoal de M. D.

Podemos, ainda, identificar outras características que direcionam às práticas de letramentos fora do ambiente escolar. Nesse ínterim, vale ressaltar que esse estudante nos apresenta um pouco da localidade onde mora: ele reside em uma fazenda com seus pais e nesse espaço considera que é 
feliz. Essa afirmação também pode ser interrelacionada à cultura do povo do campo e com a proposta de valorização dessa cultura. Em um segundo momento descreve atividades rotineiras que são realizadas tanto em de casa quanto, a exemplo do trabalho doméstico, especificando os tipos de atividades em ordem de realização. Em um terceiro momento aparece a atividade externa à casa, mas que ocorrer dentro da fazenda: o cultivo da horta junto com a mãe.

Tais atividades representam práticas de letramento a partir do momento que nos remetem a ações rotineiras daquele contexto. É exatamente com essa atividade que a estudante mantém contato com a terra e com os manejos de produção que são utilizados. Por meio dessa atividade, ele desenvolve um conhecimento que a escola deve levar em consideração em sua proposta de ensino.

Nesse âmbito, cumpre evidenciarmos que já existem alguns projetos nas escolas do campo do município de Barreiras que primam pela valorização da cultura da comunidade em que a escola está localizada. Como exemplo, de acordo com a direção da escola em estudo, os projetos "Despertar", que apresenta em sua proposta características da agricultura do agronegócio, e o projeto "Horta na escola", que se aproxima mais da proposta da agricultura campesina.

Nesse caso em questão, observamos que o estudante demonstra ter uma relação de pertencimento com sua comunidade, pois logo no início do seu texto deixa evidente seu lugar de fala. Fica evidenciada, também, sua intrínseca relação com a escola, posto que ele logo faz referência a ela e retoma isso em vários momentos ao mencionar como é sua vida fora do ambiente educativo.

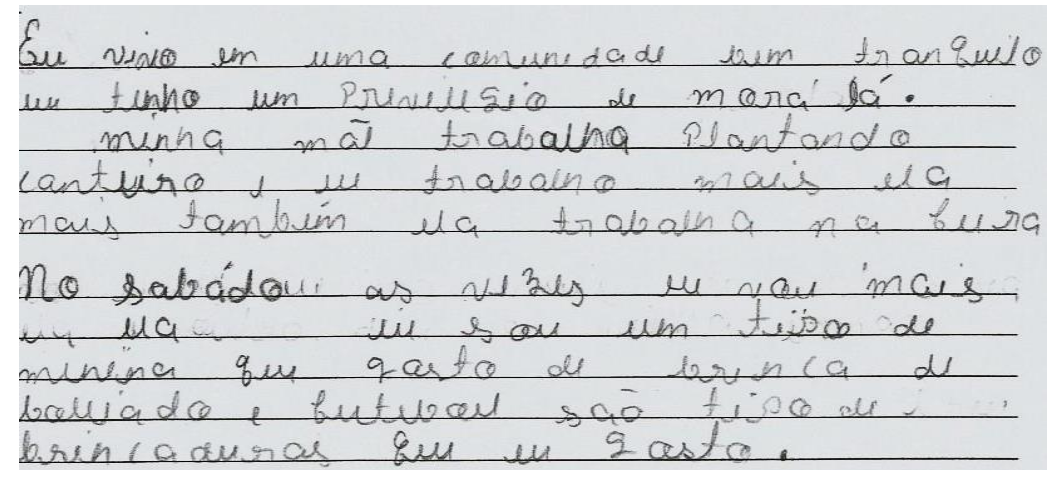

Figura 6 - Fragmento autobiográfico - Fonte: arquivo pessoal de M. D.

A fala do estudante é reveladora, posto que usa o adjetivo "privilégio" para falar da comunidade onde reside, citando que ela é bem "tranquila". Isso evidencia sua consciência quanto à questão da violência de muitos bairros e comunidades. Sua narrativa também traz indicativos de sua relação de pertencimento.

Conforme Ramos et al::

o sentimento de pertença é o que vai criar o mundo para que os sujeitos possam existir, uma vez que a condição para o desenvolvimento das suas competências e dos seus valores é a pertença a um lugar. É a partir dele que o ser humano elabora a sua consciência e o seu existir neste mundo. Pertencer significa se reconhecer como integrante de uma comunidade e um sentimento que move os sujeitos a defender as suas idéias (sic), recriar formas de convivência e transmitir valores de geração a geração (RAMOS et al., 2004, p. 36).

Nesse sentido, o sentimento de pertença é complexo e particular, pois é ele que dá a tônica para que criemos as representações de mundo e isso perpassa as questões socioculturais e identitárias. A partir desse sentimento de pertencimento, nos vemos como produtores e também 
produtos do contexto e assim lutamos em busca de melhorias para nossa comunidade, pois sabemos que esse é nosso lugar no mundo, onde nos sentimos felizes e inseridos socialmente.

No fragmento abaixo, a estudante, ao mencionar que gosta de ir à escola, demonstra que esse tem sido um espaço de convívio relevante e que lhe possibilita conhecer "novas coisas" que irão contribuir para seu crescimento enquanto ser humano. Ela menciona também que as disciplinas que mais lhe interessam são filosofia e história, pois lhe permitem conhecer mais sobre a vida. Isso revela que a escola ainda não conseguiu reestabelecer o vínculo entre as disciplinas, o que torna o saber fragmentado e, por vezes, sem sentido para os estudantes.

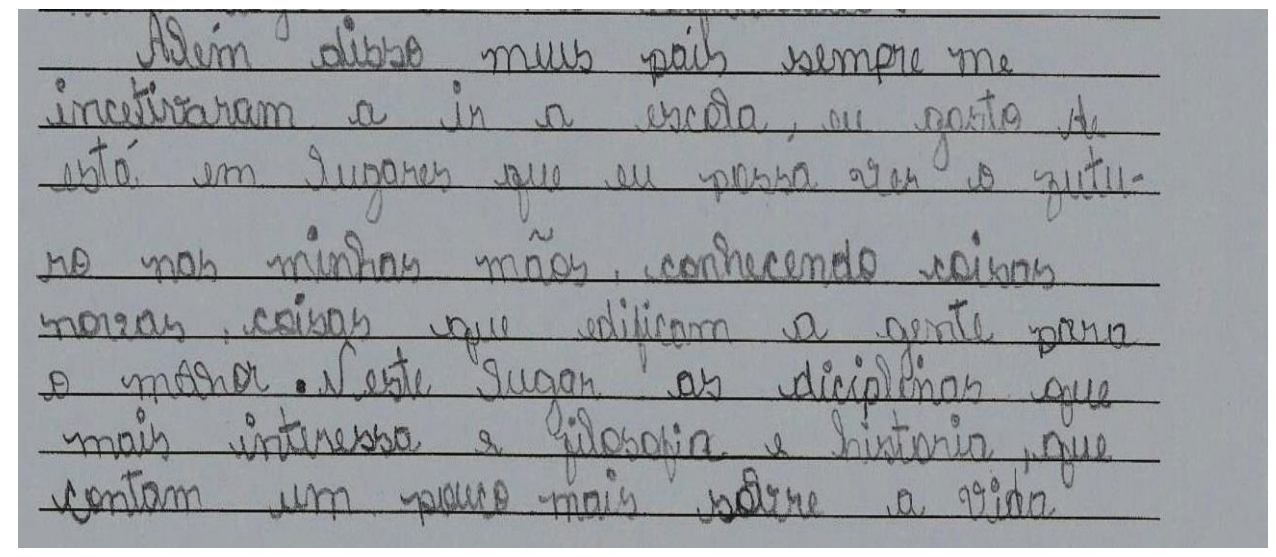

Figura 7 - Fragmento autobiográfico - Fonte: arquivo pessoal de M. D.

A escola tem relevância fundamental na formação dos vínculos entre os educandos e seu contexto, podendo influenciar negativamente ou positivamente nesse processo. Desse modo, é necessário considerar as matrizes socioculturais do contexto no qual os estudantes estão inseridos, fomentando nos sujeitos a valorização de sua cultura e do meio rural. Pois, Uma vez que se reconhece das práticas de Letramento que estão fora dos muros da escola, também é preciso compreender a maneira como os estudantes veem o letramento escolar e com isso tornar possível que esse eles queiram aprender, respeitando as experiências que vivenciam dentro da comunidade da qual fazem parte.

\section{Considerações finais}

A investigação acerca dos letramentos múltiplos na escrita de estudantes da turma do sétimo ano de uma escola no/do campo, fez-nos compreender como as diferenças socioculturais, tanto as ligadas à linguagem quanto as relacionadas às práticas estabelecidas em diferentes contextos de letramento são realizadas a partir da relação dessas pessoas com o campo, com os saberes e as diferenças encontradas na maneira como falam e escrevem.

Dessa feita, identificamos a presença forte das tradições culturais expressada pela fala de um estudante quando evidencia que ainda utiliza o cavalo para pastorear o gado, que gosta de vaquejada e quer ser vaqueiro. Com a análise de trechos das autobiografias produzidas pelos estudantes, foi possível compreender que a diversidade linguística é reproduzida na escrita deles e consequentemente, que os eventos de letramentos nos quais estão inseridos fora da escola, também estão presentes.

Diante disso mencionamos que temos nessa escola a Educação no Campo, mas não Educação do Campo, se fazendo preciso refletir e redimensionar seu projeto para a materialização da Educação do Campo. 
Destacamos, aqui, que as estratégias de análise de texto, utilizadas neste artigo, são desenvolvidas na formação dos educandos e das educandas da área de Linguagem, da Licenciatura em Educação do Campo da Universidade de Brasília, campus Planaltina, visando o olhar da realidade das pessoas do campo, em diferentes letramentos, sejam na educação básica, sejam na educação superior, em que valorizamos a cultura, a variedade linguística e a identidades das pessoas do campo, o que se insere nos letramentos múltiplos (SOUSA et al., 2016).

\section{Referências}

ANTUNES, I. Aula de português: encontro \& interação. 6. ed. São Paulo: Parábola Editorial, 2003.

ARroyo, M. G. CALDART, R. S. MOlinA, M. C. (Org.) Por uma Educação do Campo. Petrópolis, RJ: Vozes, 2004.

BORTONI-RICARDO, S. M. Educação em língua materna: a sociolinguística na sala de aula. 6 ed. São Paulo: Parábola Editorial, 2004.

BORTONI-RICARDO, S. M.; MACHADO, V. R.; CASTANHEIRA, S. F. Formação do professor como agente letrador. São Paulo: Contexto, 2010.

BRASIL. Congresso Nacional. LDB - Lei de Diretrizes e Bases de da Educação Nacional. Brasília, 1996.

BRASIL. Ministério da Educação/CNE. Diretrizes Operacionais para a educação básica nas Escolas do Campo. Brasília, 2001.

BRASIL. Constituição da República Federativa do Brasil. Diário Oficial da União. Brasília, DF, 5 out. 1988

BRASIL. Diretrizes Curriculares Nacionais para a Educação Básica. Ministério da Educação. Secretaria de Educação Básica. Diretoria de Currículos e Educação Integral. Brasília: MEC, SEB, DICEI, 2013.

CALDART, R. S. A Pedagogia da Luta pela Terra: O movimento social como princípio educativo. Porto Alegre. Disponível em: http://www.anped.org.br/reunioes/23/textos/te3.pdf. Acesso em: 20 nov. 2019.

CALDART, R. S. Caminho para transformação da escola: reflexões desde práticas da licenciatura em educação do campo. São Paulo: Ed. Expressão Popular, 2000.

CALAZANS, M. J. C. Para compreender a educação do Estado no meio rural - traços de uma trajetória. In: Jacques Therrien e Maria Nobre Damasceno (Coord.). Educação e Escola no campo. Campinas: Papirus, 1993.

ERICKSON, F. Etnografia na Educação: textos de Frederick Erickson. Rio de Janeiro: NetEdu, 2004.

FREIRE, P. Pedagogia do Oprimido. 23. ed. Rio de Janeiro: Paz e Terra, 1970. 
LEITE, S. C. Escola Rural: Urbanização e Políticas Educacionais. Coleção. Questões da nossa época. São Paulo: Cortez, 1999.

MOLINA, M. C.; SÁ, L. M. Escola do Campo. In: CALDART, R. S. et al. (Org.). MOLINA, M. C.; SÁ, L. M. Rio de Janeiro: Expressão Popular, 2012. p. 324330.

RAMOS, M. N. et al. Referências para uma política nacional de educação do campo: caderno de subsídios. Brasília: Secretaria de Educação Média e Tecnológica, Grupo Permanente de Trabalho de Educação do Campo, 2004. p. 48.

ROCHA, M. do R. O Processo de apropriação da Modalidade escrita da Língua: um estudo Sociolinguístico longitudinal. 2013. Tese (Doutorado em Linguística) - Universidade de Brasília, Brasília, 2013.

SOUSA, R. M. MOLINA, M. C. ARAÚJO, A. C. (Org.). Letramentos Múltiplos e Intedisciplinaridade na Licenciatura em Educação do Campo. Brasília: Decanato de Extensão/UnB, 2016.

ROJO, R. Letramentos múltiplos, escola e inclusão social. São Paulo: Parábola Editorial, 2009.

SOUSA, R. M. de. Gênero Discursivo Mediacional: Uma Pesquisa Na Perspectiva Etnográfica. Tese de Doutorado - Universidade de Brasília, Brasília, 2006.

STREET, B. V. Letramentos Sociais: abordagens críticas do letramento no desenvolvimento, na etnografia e na educação. São Paulo: Parábola, 2014.

VENDRAMINI, C. R. Educação e trabalho: Reflexões em torno dos movimentos sociais do campo. Cad. Cedes, Campinas, vol. 27, n. 72, p. 121-135, maio/ago. 2007. 121- Disponível em: http://www.cedes.unicamp.br. Acessado em: 26 maio 2019.

\section{Sobre as autoras}

Marta Divina Pereira da Silva: Mestra em Linguística pela Universidade de Brasília (UNBBrasília - DF). Professora da Educação Básica da rede municipal de ensino de Barreiras-Bahia. Professora Substitua da Universidade do Estado da Bahia- DCH campus IX.

E-mail: marteca25@gmail.com.

Rosineide Magalhães de Sousa: Doutora em Linguística pela Universidade de Brasília (UNBBrasília- DF). Professora Associada da Universidade de Brasília - UNB, lotada no Campus de Planaltina- DF. Líder do Grupo de Pesquisa SOLEDUC (Sociolinguística, Letramento Múltiplos e Educação).E-mail: rosineide@unb.br. 